\title{
The Learning Organization: A Foundation to Enhance the Sustainable Competitive Advantage of the Service Sector in Egypt
}

\author{
Dr. Wael Omran Aly \\ Associated professor of public administration \\ High institute of computer sciences and information systems \\ New Cairo Academy - Egypt \\ E-mail: wael.omran@ymail.com
}

Received: June 10, 2016 Accepted: July 18, 2016 Published: July 28, 2016

doi:10.5296/jpmr.v2i2.9583 URL: http://dx.doi.org/10.5296/jpmr.v2i2.9583

\begin{abstract}
An organization's capability to learn and convey that learning into action quickly, is the supreme competitive advantage. The learning organization is the structure that eases the realization of such competitive advantage, it empowers employees, it deepens and enhances the customer experience and cooperation with main business partners and eventually improves business performance. Organizational learning is considered as the suitable process to develop knowledge resources and capabilities/core competencies (human capital, social capital and organizational capital) that engender ongoing values; which in turn yield persistence superior performance; which lead to sustainable competitive advantage within the context of the strategic management.
\end{abstract}

Then, the learning organization provide the necessary organic structure involving the necessary disciplines, principles and policies; according to which the organizational learning process had to take place - in the light of the environmental surroundings- to equip the human resources with the updating knowledge, innovative capabilities, behaviors and culture representing the convenient intellectual capital to produce ongoing value stream. Such value stream deems as a sustainable competitive advantage for such organization.

This paper, therefore, explores, discusses and analyzes the integrated role of Learning organization (as a structural entity) and the organizational learning (as an intrinsic know-how process) that takes place within such context; in helping firms working in the service sector in Egypt- whether they are public or private enterprises- to achieve sustainable competitive 
advantage, as the service sector in Egypt is almost the biggest and fastest-growing economic sector and represents almost $51 \%$ of GDP. Whereby it embodies the locomotive of development for a developing country as Egypt.

Keywords: Learning organization, organizational learning, intellectual capital, strategic management, service sector.

\section{Introduction}

The service sector in Egypt is a dynamic sector, whereby the organizations working in Tourism, trade, banking, and transport services on the Suez Canal represent the main basis of service sector income. They strive to innovate their services to satisfy the changeable needs and wants of customers. Meanwhile, they are facing many challenges affecting their business such as the severe competition from global competitors, the escalated technology development and the fluctuated ecological determinants as one of the Arab spring countries.

Therefore, the research problem hereby is the disability of the service sector companies in Egypt to adapt with such environmental challenges; to keep their market positioning whether in the domestic market or the global one. Then, in order to overcome such dilemma; the organizations working in such service realm had to transform their traditional organizations into learning organizations. Which are able to absorb and substitute their traditional thinking and actions into recent knowledge and advanced practices via a group of talented employees /human resources who are continually enhancing their capabilities to create what it will take to respond to changes, complexity and uncertainty.

In fact, the degree at which the organizations learn may consider the only sustainable source of competitive advantage (Senge, 1990). Then, the creation of the competitive advantage to sustain within any organization; requires the adoption of an effective organizational learning process to make the organization adaptive - adopting changing management approach - with its internal and external environment. Moreover, to learn the organization via its intellectual capital - using innovation techniques - how to engender an appropriate persistence value stream for their market segments (productive organization).

Hence, in this paper the researcher strives - via analytical descriptive methodology- to find the answer for the following research question "how the intended learning organization can be able to enhance the creation of a sustainable competitive advantage to the service sector in Egypt?”. Therefore, the researcher aims firstly to shed light on sustainable competitive advantage concept and learning significance. Secondly, to interpret the learning organization concept and its principles. Thirdly, to suggest a strategic framework for organizational learning process into the service sector. Fourthly, to identify the challenges facing the creation of learning organization in the Egyptian service sector. Finally, to recommend the different reforming pillars necessary to convert the conventional service organizations in Egypt into effective learning organizations; applying the recent organizational learning techniques and knowledge management methods; to engender the convenient value stream that yields the intended sustainable competitive advantage. 


\section{Sustainable Competitive Advantage Concept and Learning Significance}

A competitive advantage is what differentiate you from the competitors in the eyes of your customers. Whether you are an employee, a business or a country, you need to have an adequate competitive advantage and deliver it to your customers. Before you can set your competitive advantage, you had to find out these three imperatives(Aaker, 1989):

- Final product. Whether it's a commodity or service, you've got to be very apparent on what you are producing. New technology can ameliorate that for you, so you've got to be persistently aware about how emerging trends can affect the benefits you deliver.

- Targeted market. Who are your potential customers? You must identify precisely who buys from you, and how you can satisfy them. This leads to demand augmentation, whereby it is the impetus of the economic growth.

- Competitors. This is not only other companies that produce similar products, but also anything else your customer can do to satisfy their needs.

Once you clarified these three imperatives, then you can concord what benefit you can deliver better than your competitors to your targeted market. Emphasize that message in every contact with your customers, including advertising, public relations, and even your outlets and employees. If you are the employee, treat yourself as it is your own business. Make sure your competitive advantage is manifested in your appearance, your attitude, and in how your interact.

A company must set lucid goals, strategies, and operations to sustain its competitive advantage over time. The organization culture and espoused values of the employees must be in association with those goals, too. It's difficult to realize this issue well, therefore very few companies can create a sustainable competitive advantage.

There are three major methods that companies can follow to realize sustainable advantages; they are: cost leadership, differentiation and focus. Although these main strategies were elaborated by researching companies, they can be constructive for everyone, from employees to countries, who is in quest to be notable. They are as follows (Porter, 1985):

Cost leadership means you grant equitable value at a lesser price. Companies do this by constantly enhancing operational efficiency. They generally pay their workers less, either by afford intangible incentives such as stock alternatives, benefits or promotional occasions, or by manipulating the unqualified workforce excesses. As they grow, they can profit from economies of scale, and buy in bulk. Nonetheless, regularly they pay under the cost of dwelling. Their advantages can be exposed if they ought to conform with better minimum wage laws.

Differentiation signifies you've a robust company that certainly imparts the way you deliver values significantly better than others. A manufacturer can accomplish differentiation by means of providing a exclusive or high-best product, with the aid of offering it turbo, or by way of marketing it in a way that virtually attains patrons better. Alternatively of being a cost chief, the manufacturer with a differentiation process can set a best price. In other words, they 
mostly have better profit margins. Businesses frequently recognize differentiation with innovation, exceptional or exact patron service. Innovation approach you fulfill the identical purchaser wants in a brand new manner. Exceptional manner you supply the excellent product or service, and so possibly larger priced. Customer service method discovering methods to please the customer.

Focus means you serve your target market better than anybody else. You could undertake either a price leadership or differentiation strategy, however you needed to apply it to one precise goal market. Ordinarily it's a bit of slot that has no longer being served yet by way of higher firms. Banks and tourism corporations are examples of sectors that use a focal point method to reap sustainable competitive advantage. They aim neighborhood, small organizations, or high classification invaluable members. Their targeted customer enjoys the private contact that such organizations is also ready to provide, and they're capable to pay a bit more in cost for this service. These firms are using a differentiation type of the point of interest technique.

Consequently, the sustainable competitive advantage (SCA) is when The organizations strive to realize exact traits so as to distinguish themselves from competitors in the eyes of the patron for a protracted period of time (Hoffman, 2000). Then, Competitive advantage exists when a specific company performance constantly overpasses other companies in the same industry. A company can overpass others if profits are higher than the competitors' profits. The competitive advantage is deemed to be stronger when it persists for a longer period of time. Those companies who are able to retain a competitive advantage for many years are considered to have a sustainable competitive advantage. If the sustainable competitive advantage is reliant on retaining a higher profit margin than other companies in the same industry, how does a company start to develop a strategy to both accomplish and keep competitive advantage? The two main constituents of profit are that customers both appreciate the goods and services and will pay for them and that a company can maintain production costs related to goods and services at a low level, so that there will be a higher profit margin (Njuguna, 2009).

Thus, Competitive advantage entails conveying a greater apparent value to a targeted market than its competitors can afford. This can be realized through many ways including providing a better-quality product or service, minimizing prices and increasing marketing endeavor. On the other hand, Sustainable competitive advantage means preserving an advantageous marketing positioning on the long run, which can help enhance a company's appearance in the marketplace, its value assessment and its future profitability likelihood. It is the capability to furnish superior patron price on lasting or carrying on with groundwork, a difficulty where competitors are crippled to emulate the company's potential for value construction (Collis \& Montgomery, 1995). Sustainable competitive advantage evolves when the firm's resources are priceless and high-quality (the resources support the firm create priceless and invaluable products and offerings), scarce (rivals wouldn't have entry to them), precise (opponents can't effortlessly imitate them) and suitable (the company owns them and might take advantage of them at will) (Barney, 1991). Gaining and retaining unique efficiency and incredible value stream are a function of the resources and capabilities dropped at the competitors; representing the sustainable competitive advantage (Aaker, 1989; Barney, 1995). 
Learning and knowledge management is rising as a key aspect to handle trade and developing competitive advantage. These abilities assets and capabilities, due to finding out procedures involves an enhancement in reply capacity via a much wider awareness of the environment (Dodgson, 1993; Sinkula, 1994).

Learning exists in any organization because of the inherent aspects of participants and is an unavoidable element of organizational existence. However, whether or not or no longer it's mentioned and employed will confirm the success of any group (Rebelo \& Gomes, 2008). Learning organizations are able to endure change much less painfully than non-finding out businesses because the resistance is decreased from the company having a shared vision. They auxiliary argue that it's not knowledge itself that produces a competitive advantage however as an alternative how the skills is created and infused again into the group's current competences via a robust organizational learning method (Marshall, J., \& others, 2009).

Taking this argument in addition, the resources themselves do not result in competitive benefits but rather what an organization is equipped to do as a consequence of these resources; that is what's called a corporation's core talents and Capabilities which entail the formation of complex inside items between individuals and other resources which lead to sustainable competitive advantages (Murray \& Donegan, 2003). It is through studying that these skills are created and realized. In equivalent, the existence of learning culture and the establishment of an atmosphere that eases and encourages steady learning generally is a giant factor in realizing priceless results and organizational progress imperative to engender a sustainable competitive knowledge, this is what the learning group aim to achieve (Smith, 2004).

\section{The Learning Organization Concept and Perspectives}

learning organizations (LO) May also be outlined as businesses where persons continually spread out their capability to fully grasp the outcome they truly want, the place new and wide configurations of considering are developed, the place cooperative ambition is emancipated, and where individuals are constantly finding out to see the entirety collectively. The major groundwork for such firms is that in instances of quick change best these which can be flexible, adaptive and productive will be successful. For this to take position, corporations have got to detect how you can exploit people's dedication and ability to be trained in any respect stages (Senge, 1990).

As every person has the potential to learn, the structures in which they need to perform are in general no longer causal to consideration and commitment. Additionally, individuals would possibly not have the instruments and main strategies to realize the occasions they confront. Finding out firms are constantly stretching their potential to construct their future; which necessitates a principal trade of mind among their contributors. In keeping with this, a learning organization is chiefly expert at ordinary main issue solving and is better ready with the vigor of verbal exchange and information technology to confront bobbing up challenges in the outside atmosphere (Trim \& Lee, 2004). A studying group can be defined as "an organization that concentrates on setting up and using its knowledge and capabilities knowledge so as to produce better-valued information and abilities, to change behaviors and enhance outcomes”, which yields a competitive knowledge (King, 2001). Moreover, the 
learning enterprise is a vision of what probably possible. It isn't realized simply by using training contributors; it will possibly best take place for that reason of learning propagation on the whole group stage. So, a finding out organization is an organization that eases the educational of all its members and consistently develops itself (Pedler et al., 1991).

Learning organizations are featured with the aid of aggregated worker engagement in a process of shared handling, cooperatively responsible alternate directed in the direction of mutual values or standards (Watkins \& Marsick, 1992). From theses definitions we see that for learning companies to be successful there have to be a amendment in habits, studying in itself is a change method for enhancement to adapt with quite a lot of external atmosphere forces. We are able to additionally presume that a corporation needs to appraise and make the most inside useful resource to supply and preserve competitive advantages.

\subsection{Learning Organizations Perspectives}

In compliance with the evaluation above, organizations that desire to emerge as studying businesses; needn't simplest to be able to engender new expertise, but to make use of it in a realistic way- to follow what they recommend, as it were. This isn't as effortless as it appears. Many corporations are ready to create new advantage, corresponding to from patrons, from the shared wisdom of their participants or from the sector taken as a entire, but actually don't use this expertise as good as it may occur. Garvin (1998) for illustration would see the ability to carry talents quickly across the organization as one of the crucial principle machinery of a studying group, as well as the capability to test and be trained from expertise. A helpful set of what a finding out organization would absolutely seem is imparted by means of Yang, Watkins and Marsick (2004). They recommend five perspectives, as follows:

\subsubsection{A System Perspective}

Within the context of systems ideas, learning organizations can not only adapt to alterations in their trade environment, but in addition have the potential to make their own future. The 'fifth discipline'- systems thinking- is relied on interrelationships between organizational proceedings and approaches as a substitute of linear purpose - result chains, and to be able to peer the entire approach of change as a substitute of 'snapshots'. The opposite four disciplines are team learning, where the weight is on the learning pursuits of the workforce rather of being on the progress of crew procedure, mutual visions, that are displayed in an advantage to establish a customary image for the long run that helps engender actual devotion instead than obedience, collective mental units, which are inside photos of how the world works, and individual mastery, which implies consistently illuminating and expanding private imaginative and prescient, concentrating energies, growing patience and seeing truth impartially.

\subsubsection{A Learning Perspective}

Some coincided areas are clarified in which a learning organization eases the learning of its workers. The procedure is relied on integrating the conventional elements of management to hold studying in any respect organizational phases (Peddler \& others, 1991) . For instance, they advocate adopting a learning approach to technique as good as collaborative coverage 
making. Basically this implies linking as many humans as is right in these routine to each offer enter and support distribute output. Other priorities contain the founding of a learning environment and self-progress for each person. These standards are about making possibilities for individuals to connect in finding out inside the workplace as good as eliminate boundaries impeding them from realizing so.

\subsubsection{A Strategic Perspective}

This strategy is relied on the necessity to understand the important strategic impetuses necessary to establish learning capability. For instance, learning organizations have five general strategic building blocks (Goh, 1998). These contain clearness and reinforcement for mission and vision; mutual management and dedication; a culture that advocates testing; the ability to carry advantage across organizational borders; and workforce working and cooperation. In addition, the strategic constructing blocks need two foremost helping basics. The primary is an robust institution constitution that's regular with and espouses them. The second includes the handy employee abilities and competencies needed for the tasks and roles portrayed there. These strategic constructing blocks can work as feasible recommendations for operational and managerial follow, and with the two prior helping foundations they can also offer advice for administration and organizational authorities.

\subsubsection{An Integrative Perspective}

An aggregated model of a learning organization is endorsed. It signified the process of learning inside a learning institution as incorporated with work of the group. Actually, group workers are united around a shared imaginative and prescient, whereby they're mindful of it and may adapt to their altering atmosphere (Watkins \& Marsick, 1993). Then, they generate new capabilities which they use, to provide innovative products and offerings to meet consumer wishes. Seven certain but included dimensions of a learning group at individual, group and organizational levels are clarified. These entail persistence studying; inquiry and dialogue; workforce finding out; empowerment; entrenched programs; system hyperlink; and strategic leadership. The learning organization is considered as one who has the potential to incorporate persons and constructions so as to realize ongoing learning and change.

\subsubsection{Building Blocks Perspective}

Yet another robust view of what contains a learning organization, whereby it pertains creating, acquiring and transferring knowledge and altering behavior to copy this. Three expansive motives, entitled 'constructing blocks', seen most important for organizational learning and adaptability are identified (Garvin \& others, 2008). They are a recommend learning atmosphere, solid learning processes and practices and leadership that supports learning. An advocate studying atmosphere includes a number of elements. Psychological protection is one. It must be adequate for folks to inquiry authority but also for them to be competent to admit about errors. To do that the same learning climate need to mirror an approval of differing tactics and aspects of view. It need to therefore be disclose to new strategies and undergo a measure of danger dealing with. In the end, suggest learning environments permit time to indicate what's being accomplished and the way it's being carried out. The second 
constructing block, strong learning methods and practices, emphasize the creation, interpretation and dissemination of inside and external knowledge across the organization. It is about having structured ways of obtaining and sharing data from clients and the business environment as good as from staff by way of their expertise, the initiatives they convey out and the trade issues they resolve. These tactics and practices support the motive of getting knowledge to those who will use it. The third constructing block, leadership that helps learning, requires leaders far and wide the group who're capable to support communication, to listen to diverse aspects of view, and generally to adopt a learning culture.

\subsection{Effective Learning Organization Requirements}

Despite the distinctive establishing facets for the strategies and the views outlined above, some usual concepts for the learning group effectiveness may also be seen inside them, as follows (Cyril Kirwan, 2013):

- At the strategic stage, a meaning of vision (and in certain shared imaginative and prescient) is apparent in all the organizational phases. Obvious targets, and backing for these ambitions are large if the organization is to exploit the educational opportunities that emerge from the challenges it confronts.

- There may be also the need for leaders (in any respect organizational phases) to impart the imaginative and prescient (sharing leaders). This will have to lead to better performance due to the fact that routine will also be aimed extra adequately to the pursuits, but additionally considering the fact that the larger individuals that understand and impart the imaginative and prescient, the bigger would be the quantity of learning.

- A further essential principle that appears to be principal to learning organization has to do with the formation of a learning constitution that's bendy and adaptable to alterations within the external environment. This structure should ease the production, maintenance and switch of sensible capabilities that can be utilized within and throughout organizational limitations.

- The proposal of a learning environment, where personal mastery, self-progress for everyone, schooling and training and persistence studying (exceptionally practical) are entrenched to cope with the institution pursuits. This form of atmosphere also helps testing, empowerment and dialogue and organizes teams in order that they work with and be taught from each and every other. The vigor of a finding out atmosphere may even be visible in emotional defense, in time given for contemplation and in mutual management and participation.

- The importance to generate steady learning possibilities. In finding out corporations, studying is viewed into work in order that folks can be trained on the job and opportunities are afforded for continuous schooling and progress.

- The value to inspire query and discourse. In this instances, contributors build up inventive logic competencies to state their views and the potential to listen and query into the outlooks of others, The culture is such that it encourages inquiring, suggestions and checking out.

- The significance to help cooperation and staff learning. What this denotes for the organization is that work is deliberated to employ groups to get into different varieties of 
thinking. Businesses are projected to work and learn collectively, and cooperation is liked and rewarded.

- It's important to construct understanding technological know-how programs to accumulate and share learning. Both high- and low-information technology methods to impart learning are established and integrated with work. It's value that access to those systems is granted, and that they are sustained.

- There is a necessity to empower individuals to a shared imaginative and prescient. People within the group turn out to be implicated in striking, possessing and making use of this imaginative and prescient. Responsibility needed to be dispersed virtually determination making so that employees are provoked to learn to what they are detained in charge to do.

- It is imperative to bond the organization to its atmosphere. Contributors are aided to peer the result of their work almost always company. So as to do that they analyze the atmosphere and utilize know-how to keep an eye on work practices, and the institution is hooked up to its environment.

- The firm has to impart strategic management for learning. Leaders need to increase, advocate and maintain learning, and ought to exploit learning in a strategic method for business effects.

It's clear from the argument above that becoming a learning institution is an ending to which many organizations hope, given its associations with performance and competitive advantage within the economic context. How therefore can the various aspects and concepts sketched be included to construct such an entity? It can be only realized via the organizational learning process; liable to create and share skills inside the organization. Then, growing the intellectual capital; which embodies the heart of the learning organization and its key competitive advantage.

Accordingly, a learning organization must have the ongoing ability to acquire, retain and transfer knowledge by way of an effective organizational learning method to regulate the behavior of its staff participants to breed new knowledge, talents and insights; which may also be exploited by using such institution for the accomplishment of improved efficiency and then sustainable competitive advantage.

\section{Strategic Framework for Organizational Learning Process}

It's essential to distinguish between "learning group” and "organizational learning”, they deem that these ideas must no longer be regarded as they're identical (Graham \& Nafukho, 2007). A learning organization is involved in making a metamorphosis in behavior in an effort to behavior the company to fully grasp its preferred reworking (Blackman \& Henderson, 2005). The learning organization (LO) embodies the monitor of the group in a definite structural framework; even as organizational learning (OL) is deemed as enormous operative software used to encapsulate the training movements within the organization (Garavan, 1997). The two terms are unique but strongly interrelated; organizational learning needs to achieve a segment where the switch of learning and sharing of knowledge is simpler 
(Sun \& Scott, 2003). Although learning organization is an analysis of how companies learn, the preliminary factor will perpetually be a scrutiny of how contributors learn. In parallel, the organizational learning is deemed an approach to categorical that organizational members own the potential to be trained jointly. Then, organizational learning is pertained as a knowledge sharing method; additionally, the competitive strategy of the institution that can engender its sustainable competitive advantage (Hoyle, 1995).

\subsection{Organizational Learning as a Knowledge Sharing Process}

Organizational learning implies the complete of individual and sharing learning by way of training programs, follow, trying out and work interactions inside the institution. It's the acquirement, provisions or altering of values shared through people via cultural instruments and through the cooperative movements (Cook \& Yanow, 1996). However, the proposal of organizational learning is keen on rival formulations and is a permanent argument (Stewart, 1996). Most definitions that handle the learning approaches; are embedded in social and cognitive psychology (Lipshirtz, 2000). However, organizational learning is outlined as a method of synchronized methods exchange, with ways inherent for participants and organizations to get into, establish and make the most organizational memory, structure and tradition to construct up long term organizational capability (Miller, 1996). It's a full of life process of construction, acquirement and integration of knowledge meant at the development of resources and advantage that lead to better organizational performance (Lopez, Peon, \& Ordas, 2005). Even as a special illustration of organizational learning could also be convenient for other businesses to emulate, ongoing organizational learning has increasing effects which might be extra intricate to emulate (Denisi et al., 2003). Prior reviews have identified four facets or phases of organizational finding out process to be potential acquisition, distribution, application and translation into organizational reminiscence. Nonetheless, the organizational learning can also be featured as an difficult three-stage method comprising of abilities acquisition, dissemination and shared implementation (Huber, 1991; Dale, 1994; Nevis Debila \& Gould, 1995; Winter, 2000).

Mainly, the stages of organizational learning process can be illustrated at six consecutive steps (see fig.1), which continuously repeat themselves in the strategic management context as follows (Pawlowsky, 2003) (Katie Smith \& others, 2011) (Omran, 2015):

1. The definition of internal and external actors who create and use knowledge (the learning community vision and mission)

2. The clarification of the learning needs and the information that appears pertinent to learning, to the creation of latest knowledge, or both in the context of the internal and external environment factors relevant to the organization (learning strategic goals).

3. The trade and dissemination of knowledge, either from the employee to the shared stage or at the shared stage itself by clarifying the excessive worth sources of knowledge (learning priorities and plans).

4. The blend of competencies into obtainable skills techniques at a shared level, an individual stage, or both, or into procedural rules of the group, by using opting for techniques for each 
and every steps whereby both amalgamation and adjustment of the adopting procedure can take place (learning policies and programs).

5. The conversion of the brand new expertise into action and the induction of the expertise into organizational routines, in order that it affects the organizational conduct (e.g. The development of recent management styles or new products and offerings) (learning action plan).

6. Integrate resources such as staffing, incentives and maintain new knowledge abilities for creation to ascertain its effectiveness; by monitoring and evaluating periodically the organizational learning progress in realizing the intended learning goals to a successful knowledge sharing process (learning evaluation \& feedback).

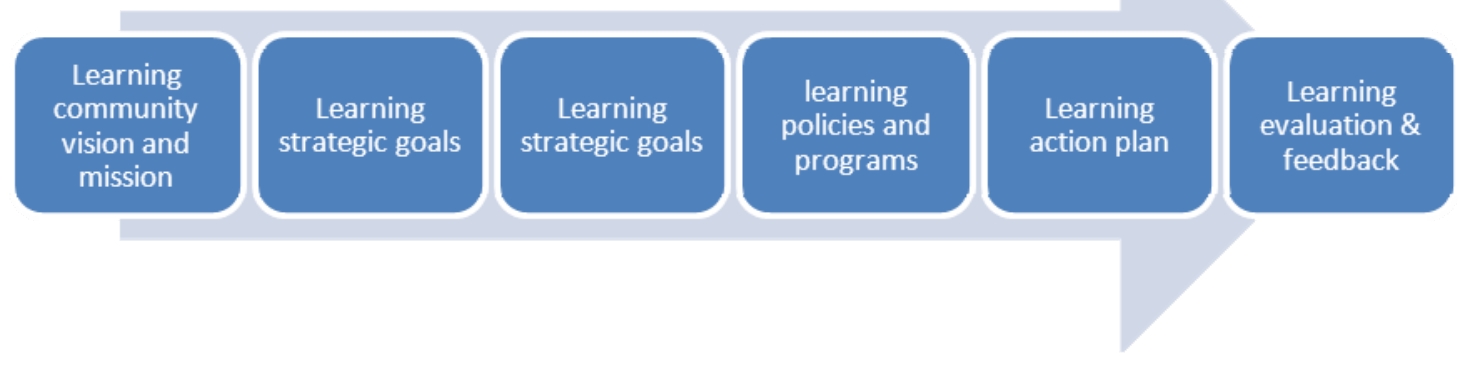

Figure 1. Organizational learning process

\subsection{Organizational Learning as a Competitive Strategy}

Organizational learning procedure -as we aforementioned- entails capabilities acquirement, dissemination, software and conversion of this capabilities into organization assets (organizational memory) akin to databases, methods and programs that can be useful to uplift the organization. Because of this, when a firm attain person level advantage resources (human capital) by means of selection, training or observe and different learning activities, it must find a way to convey those resources to the group stage and ultimately to the organizational degree (Denisi, 2000). In any other case, the penalties of these talents-centered assets on competitiveness will probably be inadequate. The firm must construct up methods, methods and techniques (organizational capital) - on the organizational level- by way of which contributors which have the principal expertise can bring this information to others who can use it. This requires that for an institution to profit from the learning approach, it must lay some exertion within the knowledge management.

Moreover, it's via social capital, knowledge exchanges between all stages can take location, that's, from person to organizational to inter-organizational and vice-versa (Autio Yli-Renko \& Sapienza, 2000). This social capital is generally expressed as an asset implanted within the relationship of individuals, committees, networks or societies (Coleman, 1998). 


\section{Ml Macrothink}

Hence, These three aforementioned strategic principles of intellectual capital signify that at the same time it is participants who create, preserve and use skills (human capital); this advantage is increased by using the social interactions and networks (social capital) to engender the institutionalized advantage possessed by an organization (organizational capital) (Armstrong, 2001). Gaining and maintaining sustainable competitive advantage and improved performance are a cause of the resources and capabilities brought to the competition (Aaker, 1989; Barney, 1995). These knowledge resources and abilities, as a result of learning tactics entails an enhancement in responding abilities through a much broader comprehension of the atmosphere (Dodgson, 1993; Sinkula, 1994). It says that a corporation can accomplish over average efficiency for an extended period of time if it follows organizational learning approaches that yield competitive advantage and are too hard to emulate. As a result, human, social and organizational capital (intellectual capital) combined with effective knowledge management techniques to boost the switch of knowledge via the bounds of participants, departments, units and corporations conduct to sustainable competitive advantage (Njuguna, 2009). This model is represented in Figure 2:

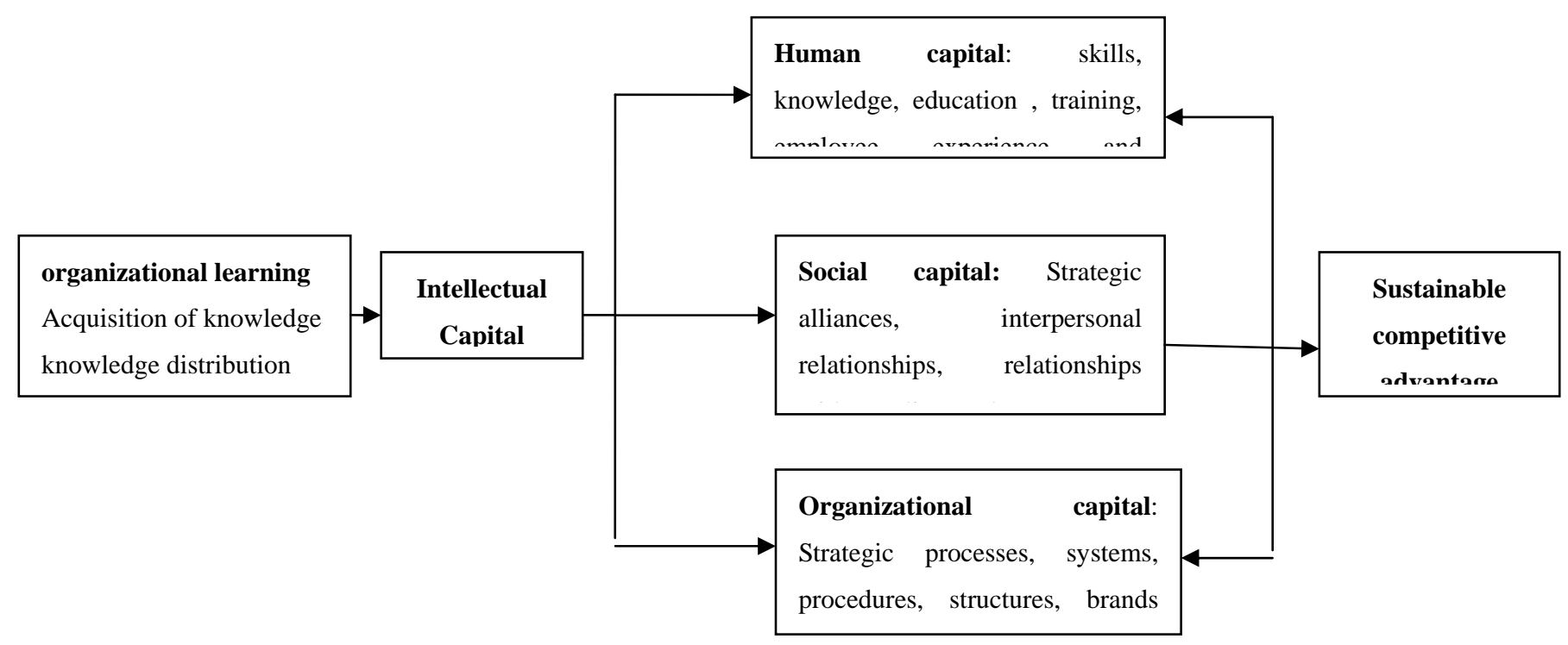

Figure 2.

It is fundamental to mention hereby that the organizational learning is a strategic dynamic double loop method that does not occurs most effective by means of time, but additionally by means of distinctive levels or aspects of the organization (Oyeniyi, 2011). The dynamics is developed through the strain between the organizational exploration and amalgamation of new abilities developed at individual level (feed-forward), and individual exploitation of organizational pre-current expertise (feedback) (Crossan \& Hulland, 2002).

Accordingly, there are important connotations in balancing the tension between Exploration and Exploitation (Crossan, 2004). Because the firm that manages good organizational learning is able to create new and revolutionary recommendations, as well as institutionalize and get learning to the contributors and appoint it within the organization. 


\section{Challenges Facing the Creation of Learning Organization at the Egyptian Service Sector}

The service sector is without doubt one of the three monetary sectors; others include manufacturing sector and agriculture sector. The service sector has arisen because the lively sector whose importance has increasingly regarded in most economies considering the 1990's and 2000's. The carrier sector has extended to represent 60\% of Gross country wide Product (GNP) in most developed and setting up countries -as Egypt- while having impact on different sectors (Oyejide \& Bankole, 2001). Whereby the demand for services is somewhat sales elastic, because the economy escalates the consumption of offerings raises. The provider sector can also be principal for the reason that it imparts help offerings to other sectors; for example, it provides the manufacturing sector with designs, transportation, financing and communication. The service sector can also be well-known to provide the financial system with the easiest price of employment which sequentially results in development and progress of the economic system. With the steady growth in this sector the level and force of competitors also escalates as organizations wrestle to accumulate a larger share of the market. The contemporary shift far from manufacturing and closer to provider has shaped which means of necessity for companies to exploit their intangible resourcesknowledge, expertise and assets (Appelbaum \& Gallagher, 2000).

Egypt's economic system is the second biggest in the Arab world (after Saudi Arabia) and its fiscal sectors replicate its dimension. The service sector is the largest and quickest-developing economic sector and money owed for nearly 51 percentage of GDP. Tourism, trade, banking, and transport offerings on the Suez Canal constitute the fundamental sources of service sector earnings. In view that 2011 and till now each tourism and the Suez Canal have been hit tough by means of political uprisings and terrorism challenges; which influence the economy in Egypt and make the overseas viewers as well as investors staying away from the country. The government has moved to aggressive promoting of domestic tourism to catch up on the loss of foreign tourism, and managed to revive more than 60 percentage of the pre -2010 vacationer traffic by late 2015 (Egypt executive carrier portal). Meanwhile, the prospects of restoration in the Suez Canal sector, nonetheless, had been much less promising, with growth in that area rather sluggish, despite executive plans to revive it by digging the brand new department of Suez canal and launching the newly good value progress zone there. Accordingly lately, the rank of Egypt is retreated on the competitiveness index to 119 amongst one hundred forty four nations (world Competitiveness record 2014-2015).

Consequently, the federal government have got to strive to convert their typical non-finding out corporations into studying organizations; ready to create the mighty talents sharing procedure. Such organizational learning procedure is critical to engender the suitable intellectual capital; main to sustainable competitive advantage. For that reason, organizations working within the Egyptian carrier sector can be in a position to fortify their real and perceived market price. 
Unfortunately, there are many challenges that may impede the Egyptian attempt to create effective learning organizations to its service sector organizations; such challenges can be classified into internal and external challenges.

\subsection{Internal Challenges}

Such type of challenges shed light on the discrepancies that may exist within the internal environment of the Egyptian organizations working at the service sector and can impede its transformation to learning organizations; such challenges can be controllable by the organizations management, they are as follows (Handousa, 2010; Omran,2013; Yassin, 1994) :

- Leadership does no longer put the instance learning: The notion of organizational learning will not be supported and lessons expertise are usually not incorporated.

- Management is blinkered: management is detached from the rest of organization and the outside atmosphere.

- Management is conceited, ignorant and contented: strong egos and previous success make managers not to be willing to well known or declare their errors.

- Terrible high - down communique channel: understanding is afforded on a necessity-to-understand groundwork, with little clarification.

- Now not seeking for ideas: administration is reluctant to get excellent recommendations from staff.

- Lack of upward conversation: Upward verbal exchange is disregarded or channels are barren, and management deems productive criticism to be an offense to current strategies.

- Lack of organizational culture encouraging learning and capabilities management adoption.

- Lack of empowerment to be trained and change: slash-degree employees are not supported to take a look at new strategies or start change.

- Ineffective mental models: administration isn't tailored with present actualities and is reluctant to undertake new prospects and undertake one-of-a-kind strategies.

- Obsession with the brief time period bottom line: management concentrates on reducing costs to give a boost to gift profitability as a substitute of spending time to be trained and follow to the longer term.

- Lack of aggregated approach to vary: alterations are both too few, too many, too late or not realized well.

- Inadequate communique about alternate: administration does now not have the funds for ample conversation earlier than, for the period of, or after change.

- Fear and apprehension about exchange: administration's worry of appearing unhealthy increases the resistance for exchange; and leads it not to ask for counsel from others. 
- Change in leadership: Turnover, rotation, restructuring and being wanting continuity triggers staff to resist change.

- Inadequate training: top management does no longer present adequate time and funding for job distinct and progress interconnected training.

- Deficient method for capabilities acquirement and sharing: there is not any popular database to contribute, store, admission and distribute knowledge.

- Reluctance to make use of suitable technology: Managers and workers don't adopt new technology, involving exploiting the whole worth of the internet.

- Shortage of multidirectional communication: Departments aren't communicating with each and every different.

- Inadequate efficiency size and accountability for incompetent efficiency: staff who do super work aren't rewarded and people who do incompetent work proceed doing incompetent work.

\subsection{External Challenges}

Such type of challenges represent the external barriers that may affect negatively the transformation of the organizations working at the service sector in Egypt, such barriers exist in the external environment surrounding the organizations, they are uncontrollable by the organization. In other words, such barriers had to be handle via outer actors as the government and other societal agencies. These barriers are as follows:

\subsubsection{Lack of Political Foresight and Dedication}

The foresight and commitment of political management work as motivating forces to recognize the learning organization model in service sector. In Egypt, few political governments tried to reform the provider firms with a purpose to set the standards and factors of studying organization (Omran, 2013). The motives include: a scarcity of expertise in regards to the learning organization and the organizational learning methodologies, the mentality of lengthening the vigor, the shortage of dedication and the fact that political leadership has under no circumstances been genial of their effort to restore the walking method of the non-learning organizations into learning organizations capable to adapt with the external environment and produce the appropriate intellectual capital, that yields the intended sustainable competitive advantage at the service sector market (Fawzy Henien, 2007; Khan, 1998).

\subsubsection{Apathetic Governments}

The government wants ability and rigorous efforts to execute the learning group mannequin in the carrier sector by means of reforms. For decades, virtually all governments in Egypt have glumly didn't exhibit a distinct capacity to have an understanding of the strategies of the reform committees involving the need of the learning organization construction (Omran, 2015). 


\subsubsection{Corruption}

Corruption is extremely entrenched in all aspects of lifestyles in Egypt. The whole economical sector as good as the service sector has been overwhelmed by both political and administrative corruption in a type of bribery, misuse of authority, partiality, benefaction, thievery, and deception (Fadel, 2011). These phenomena have already emerged as a factor impeding the learning organization-form reforms in Egypt.

\subsubsection{The Retreat of Society Culture and Awareness about Knowledge Importance}

The values of learning and knowledge creation in the Egyptian society are almost fainted. Thus, the societal organizations didn't advocate learning organization model to be adopted at the service sector realm; in spite of its importance in the sustainable competitive advantage creation (Egyptian Cabinet IDSC, 2011).

\subsubsection{Deplorable Information Technology Infrastructure}

The information technology infrastructure in Egypt is still uncompleted. As Egypt began from several years an ambitious project to apply the e.government; but unfortunately such project is crippled by the red tapes, corruption, the shortage of technical and financial resources (Khawaga, 2007).

\section{The Reforming Pillars Necessary to Create Effective Learning Organizations at the Egyptian Service Sector}

Making the transformation to the learning organization, in the context of the aforementioned effectiveness requirements, is challenging as technology and management information systems may need to be improved, and employees must seriously develop their knowledge of learning organization (Egyptian Ministry of Planning, 2012). The process of becoming a learning organization requires the adoption of good governance indices -as participation accountability, transparency, etc...- as well as the new service management principles (market oriented) by the organization. In short, the learning organization creation in the Egyptian service sector requires the adoption of some important reforming pillars -as a prerequisite- to overcome the aforementioned challenges and barriers. In this context, it is important to differentiate between these reforming pillars, whereby some of them are internal related to the organization management approach and techniques, and others are external related to the progress of the external societal forces that surround the organization affecting its works.

\subsection{The Internal Reforming Pillars}

Such pillars are essential to transform non-learning organizations into learning organizations; able to share knowledge and to create the appropriate intellectual capital. Then, to engender the value stream which yields the sustainable competitive advantage in the service sector in Egypt. These reforming pillars had to be fulfilled in the first place by the management of the organization itself to overcome the aforementioned internal challenges. Such pillars tend to revamp the structures (restructuring), the activities and the procedures (reengineering) and the people (human resource approach) within the organization. On other words, they focus on the governance of the organization. The occurrence of such reforming pillars is essential to create 
the intended learning organization. Such pillars represent the motivator factors that yield learning organizations; they are as follows:

\subsubsection{Managerial Reform}

The intended managerial reform key factors in Egypt ought to incorporate more than a few forms of decentralizing management, the creation of self reliant agencies and devolution of budgets and monetary control, growing use of markets and competitors in the provision of offerings (e.g., contracting out and different market-style mechanisms), and growing emphasis on efficiency, outputs, effects and customer orientation (Larbi, 1999). Thus, The common model of organization and supply of services, established on the concepts of bureaucratic hierarchy, planning, centralization, direct control and self-sufficiency, as within the case of Egypt, is being changed by way of a market-based service management, or enterprise culture (Caiden, 2001). Conclusively, the important thing factors of management reform to be utilized in Egypt realizing the learning organization mannequin had to be as follows (Pollitt, 1994) (Lynn, 1996) (Cyril Kirwan, 2013):

1. The need for leaders (in any respect organizational levels) to apply the strategic administration methodology and to share their strategic visions (sharing leaders). This should influence in higher efficiency on account that routine can also be aimed extra effectively in the direction of the targets, but additionally on account that the more humans that understand and share the imaginative and prescient, the bigger would be the quantity of learning.

2. A change in the focus of management from inputs and methods toward outputs and outcomes, consequently, adopting the result situated administration is a necessity. Whereby a stress on dimension and quantification is critical, primarily in the type of programs of performance indicators.

3. The creation of a learning structure that is flexible and adaptable to changes in the external atmosphere. This constitution should ease the creation, upkeep and switch of useful capabilities that can be used inside and crosswise organizational restrictions. Then, the favorite of lean/flat and impartial organizational types: decentralization (i.e. Let the managers manipulate / the right of managing).

4. Extra customary use of market-kind mechanisms (MTMs) for the supply of services (quasi-market options, compulsory competitive proposition).

5. Preferring contract- relationships rather of hierarchical relationships.

6. Customer and best orientation; with the aid of simplify the E. government use to the entire form of services to establish a fast responsiveness to folks wants and wants.

7. Adopting lean pondering approach to services management; by means of sustaining an effective worth move of value-delivered activities to fulfill citizens/customers desires in high quality, minimum fee and minimal time.

8. Embracing an organizational culture espousing values as question and talk fundamental to make a learning climate within the organization, whereby personal mastery, self-development 
for everybody, education and coaching and ongoing learning are entrenched in the best way the organization goes about its change. This type climate additionally encourages checking out, empowerment and dialogue and constructs teams so that they work with and learn from each and every other. The vigour of a learning climate may also be noticeable in emotional safeguard, in time given for contemplation and in collective management and commitment.

9. The institution need to furnish strategic leadership for learning. Leaders need to improve, aid and hold learning, and have to use learning strategically for business outcome.

10. Amendment of staffing programs, coaching and human development guides to fortify job effectiveness, efficiency and employees' satisfaction. So, the correct individual who's ready, and persuaded to use the learning organization principles and the organizational learning procedure; will fill into the proper submit.

11. Established a strong code of ethics that helps the learning group values and concepts, with a view to make the organizational culture accommodating for learning organization adoption inside the service sector organizations.

12. Managerial leaders' commitment to use learning organization standards and the organizational learning strategic framework in the service sector will facilitate the execution of organizational learning policies and procedures; and likewise will decrease the staff' resistance.

\subsubsection{Partnership}

In development organizations, as service firms in Egypt, learning organization needs to be developed on collectively useful partnership relationships relied on trust among the many stakeholders involved within the learning intervention (Garvin \& others, 2008). On other words, it is important to encourage cooperation and staff learning. Which is supposed for the organization that work is deliberate to use groups to retrieve extraordinary types of thinking. Agencies are estimated to work and be learned collectively, and cooperation is valued and rewarded.

\subsubsection{Accountability}

Shaping accountability will have to take into accounts the nature of the partnerships in the learning involvement. Where strong partnerships are there, an organizational learning method begins with mutual efficiency prospect, continues with mutual decision making process and yields ultimately to impart accountability. There is a requirement to authorize staff within the learning organization toward a shared vision. Members on this organization grow to be worried in surroundings, owning and realizing this imaginative and prescient vision. Responsibility is dispersed close to resolution making in order that humans are provoked to learn towards what they are detained accountable to do (Watkins \& Marsick, 1993). Thus, it's central to bond the organization to its atmosphere. Participants are eased to see the effect of their work on the whole firm. As a result, they examine their surroundings and handle information to adjust work manifestations, and the organization is connected to its communities. 


\subsubsection{Transparency}

Transparency is important to make sure the production of knowledge technological know-how methods inside the service corporations to maintain and share learning. Both excessive- and low-information technology methods to impart studying are fashioned and incorporated with work. It is main that entry is provided to these methods, and that they are maintained. Then, the benefits of the learning organization concepts are entirely realized. Transparency is needed in defining the imperative roles and tasks of partners for the training involvement, and particularly the success of the organizational learning system (Peddler \& others, 1991). Suitable revelation of the approaches used to create and share knowledge is primary to supply ongoing learning possibilities. In learning organizations, learning is deliberated into work in order that folks can gain knowledge of on the job and opportunities are afforded for steady schooling and progress.

\subsection{External Reforming Pillars}

Such pillars are important to ensure the propagation of the learning organization thinking in the society and to enhance its adoption as a managerial philosophy at the public and private organizations working in the service sector in Egypt. These reforming pillars had to be fulfilled in the first place via the government and other societal stakeholders -as the legislative authority and the various civil society organizations- to overcome the aforementioned external challenges. The occurrence of such reforming pillars help to create the intended learning organization; but it is not enough to be solely, it must incorporate with the other aforementioned internal reforming pillars. Such external pillars represent the hygiene system that enhance the creation of learning organizations; they are as follows:

\subsubsection{Legislative Reforming}

Legislations must be issued to support the transparency, the anticorruption procedures and the freedom of information exchange in Egypt. Furthermore, the law of service corporations in Egypt had to be modified to encourage -via various economic incentives- the transformation of non-learning organization into learning organization; able to produce, disseminate and share the necessary knowledge to realize the sustainable competitive advantage. Moreover, it is essential to modify some laws to facilitate the adoption of the learning organization in the service sector as the Egyptian laws for budgeting, governmental accounting, civil service and employment to turn into outcomes/results oriented as a substitute of being processes/regulations oriented.

\subsubsection{The Completion of the Information Technology Infrastructure}

The information technology infrastructure in Egypt had to be completed. Especially, the government matrix; whereby the government had to provide -for the achievement of such important project- the necessary technical and financial resources.

\subsubsection{Societal Cultural Awareness and Training}

Countless training programs and media campaigns in Egypt had to be planned and performed to notify publics and workers about learning organization major position in the cognizance of 
progress objectives and its positive results on the neighborhood. Accordingly, any competencies resistance for learning organization mannequin adoption on the service sector can also be evaded, and also to make members and institutions within the society aware about pertinent organizational learning approaches (Moore, 1995).

\subsubsection{Political Dedication}

The insight and dedication of political leadership needed to work as riding forces to build powerful networks of companions in a just right governance context; to implement with ease the learning organization model within the service sector realizing its sustainable competitive advantage; which is foremost for the economical progress of the society.

\section{Conclusion}

After the earlier evaluation, It is apparent that the service sector in Egypt have got to be deregulated, transforming the typical non-learning organization into a new learning organization is a must; to hold managers in charge for the creation and sharing of knowledge everywhere in the organization, via an amazing organizational process, to engender the proper intellectual capital; which could be a decisive tool to produce the integral value stream; that can represent the organizational sustainable competitive advantage. This can be an important exchange: from non-learning organization in terms of traditional procedural compliance, to learning group in terms of efficiency and outcome, whereby a strong organizational approach takes place to make such organization adaptive with its environment and productive of a value stream knowledge; that yields the potential sustainable competitive advantage.

As a result, by inspecting the identified learning organization standards and core perspectives, the learning organization necessities have been as follows: an imaginative and prescient vision is clear in the entire organizational levels to take advantage of the learning opportunities that emerge from the challenges it confronts, the need for leaders (at all organizational levels) to impart the imaginative and prescient vision (sharing leaders), the organizational constitution needed to be flexible and adaptable to alterations within the external environment to ease the production, maintenance and switch of realistic knowledge that can be utilized within and throughout organizational barriers, the adoption of learning climate where individual mastery, self-development for each person, education and coaching and persistence learning (exceptionally realistic) are entrenched to manage with the group pursuits. This variety of atmosphere also helps trying out, empowerment and talk and organizes groups in order that they work with and gain knowledge of from every other, The significance to aid cooperation and crew learning where corporations are projected to work and gain knowledge of together, and cooperation is appreciated and rewarded, the establishment of know-how technological techniques to collect and share learning creation, it is important to bond the organization to its atmosphere. Members are aided to peer the result of their work regularly corporation.

Moreover, Six cycled steps constitute the organizational learning approach strategic framework are urged for use in the Egyptian service sector. Such strategic framework will 
first of all with the definition of inner and outside actors who create and devour expertise (the learning community vision and mission). Secondly, the identification of the training needs and the expertise that appears important to finding out to the construction (iteration) of recent knowledge, or both within the context of the inner and external environment explanations relative to the group (learning strategic goals). Then, the third step is to preserve the exchange and diffusion of knowledge, both from the individual to the collective level or on the collective stage itself via settling on the high value sources of knowledge (learning priorities and plans). The fourth step is the incorporation of knowledge into existing knowledge programs at a collective stage, an individual level, or each, or into procedural rules of the institution (learning policies and procedures). The fifth step, the transformation of the brand new knowledge into action and the reapplication of the knowledge into organizational routines (learning action plan). Finally, Align resources comparable to staffing, incentives and support to new knowledge capabilities construction to ascertain its effectiveness; by monitoring and evaluating periodically the organizational learning process (learning evaluation and feedback).

Lamentably, there are diverse challenges -as we aforementioned- to the creation of an robust learning organization to the Egyptian service sector. Such challenges may also be labeled into internal and outside challenges. For that reason, with a purpose to overcome such challenges it necessitates the adoption of quite a lot of reforming pillars counting on good governance indices and market-oriented service management; such pillars will also be classified into inside reforming pillars as: Managerial reform, partnership accountability and transparency; and external reforming pillars as: legislative reforming societal cultural consciousness and training and political dedication.

Subsequently, we conclude hereby that an institution's capability to learn and convert that learning into innovative action quickly, is the supreme competitive advantage. The learning organization is the structure that eases the recognition of such competitive abilities, it empowers workers, it deepens and enhances the consumer expertise and organization with major business partners and eventually increases its performance. Organizational learning is regarded as the suitable strategic system- that takes place inside the learning organization- to boost knowledge assets and intellectual capital (human capital, social capital and organizational capital) that engender ongoing values; which in turn yield persistence superior performance; that lead to sustainable competitive advantage.

\section{References}

Aaker, D. (1989). Managing assets and Skills: the key to a sustainable competitive Advantage. California Management Review, 31(2), 91-106.

Appelbaum, S. H., \& Gallagher, J. (2000). The competitive advantage of organizational learning. Journal of Workplace Learning, 12(2), 40-56.

Armstrong, M. (2001). A Handbook of Human Resource Management and Practices (pp. 43-46). London: Kogan Page. 
Autio, E., Yli - Renko, H., \& Sapienza, H. J. (2002). Social Capital, Knowledge Acquisitionand Competitive Advantage in Technology -Based Young Firms. Strategic Management Journal, Special Issue on Entrepreneurial Strategies and Wealth Creation in the 21 Century, pp. 12-20.

Barney, J. B. (1991). Firm resources and Sustained competitive advantage. Journal of Management, 17(1), 99-120.

Barney, J. B. (1995). Looking inside competitive advantage. Academy of Management Executive, 17(4), 49-61.

Blackman, D., \& Henderson, S. (2005). Why learning organizations do not transform. The Learning Organization, 12(1), 42-56.

Caiden, N. (1998). Public Service Professionalism for Performance Measurement and Evaluation. Public Budgeting and Finance, 18(2), 35.

Coleman, J. (1998). Social Capital in the creation of Human Capital. American Journal of Sociology, 94, 95-120.

Collis, D. J., \& Montgoemry, B. (1995). Competing on Resources strategy in 1990's. Harvard Business Review, July-August, 118-128.

Cook, S. D., \& Yanow, D. (1993). Culture and Organizational learning. Journal of Management Inquiry, 2, 373-394.

Crossan, M. (2004). Old wine in new bottles. Impact - Management Research in practice - an online monthly research publication by the Ivey Business School, (May), 8(4), 3-11.

Crossan, M., \& Hulland, J. (2002). Leveraging Knowledge through Leadership of Organizational Learning. In Choo \& Bontis (Eds.), The Strategic Management of Intellectual Capital and Organizational Knowledge (pp. 711-723). New York: Oxford University Press.

Dale, W. (1994). Learning Organizations in Managing Learning (pp. 22-31). London: Routledge.

De Geus, A. (1988). Planning as learning. Harvard Business Review, 66, 70-74.

DeNisi, A. S. (2000). Performance appraisal and performance Management: A multilevel analysis. In K. Klein \& S. Kozlowski (Eds.), Multilevel theory, Research and Methods in Organizations (pp. 11-18). San Francisco: Jossey-Bass.

DeNisi, A. S., Hitt, M. A., \& Jackson, S. E. (2003). The Knowledge Based Approach to Sustainable Competitive Advantage (pp. 38-49). New York: Oxford University press.

Dodgson, M. (1993). Technological learning, technology strategy and competitive pressures. British Journal of Management, 2, 3.

Egyptian Cabinet IDSC (Information and Decision Support Centre) Egyptian Consumer's Trust Index in Economic Performance, 2011. 
Egyptian Ministry of Planning. (2012). The Strategic Framework for Economic and Social Plans in Egypt till 2022, A Proposition Paper (pp. 2-44).

Fadel, M. (2011). Public Corruption and the Egyptian Revolution of January 25: Can Emerging International Anti Corruption Norms Assist Egypt Recover Misappropriated Public Funds? Harvard International Law Journal Online, 52, 11-19. Retrieved October 5, 2011, from http://www.harvardilj.org/online/

Fawzy Henien, S. (2007). Egypt: Bad Blood. In J. Werve \& Global Integrity (Eds.), The Corruption Notebooks. Washington DC: Global Integrity.

Garavan, T. (1997). The learning organization: a review and evaluation. The Learning Organization, 4(1), 18-29.

Garvin, D. A. (1998). Building a learning organization. Harvard Business Review on Knowledge Management. Boston, MA: Harvard Business School Publishing, 47-80.

Garvin, D. A. (2000). Learning in Action. A guide to putting the learning organization to work. Boston, Mass.: Harvard Business School Press, pp. 74-82.

Garvin, Edmondson \& Gino (2008). Is Yours a Learning Organization? Harvard business review, 1-10.

Ghoshal, F., \& Morgan, L. K. (1996). Cited by DeNisi, A. S., Hitt, M. A., \& Jackson, S. E. (2003). The Knowledge Based Approach to Sustainable competitive Advantage (pp. 24-26). New York: Oxford University Press.

Goh, S. C. (2003). Improving Organizational Learning Capability: Lessons Form Two Case Studies. The learning Organization, 10(4), 216-227.

Graham, C. M., \& Nafukho, F. M. (2007). Employees’ perception toward the dimension of culture in enhancing organizational learning. The Learning Organization, 14(3), 281-292.

Hoffman, N. P. (2000). An Examination of the Sustainable Competitive Advantage Concept: Past, Present, Future. Academy of Marketing Science Review, p. 4.

Hoyle, E. (1995). The school as a learning organization. paper presented at the AERA Conference, San Francisco, CA, April, pp. 5-12.

Huber, G. P. (1991). The Contributing Processes and the Literatures. Organization Science, 2(1), 88-115.

Khan, Administrative Reforms in Bangladesh, Dhaka: University Press Limited, 1998, pp. 10- 22.

Khawaga, O. M. (2007). Challenges and opportunities for e. government application in Egypt , Cairo university, faculty of economy and political sciences, economical research and studies Centre. Economical papers, 35, 5-9.

King, W. R. (2001). Strategies for creating a learning organization. Information Systems Management, 18(1), 12-20. 
Kirwan, C. (2013). Making sense of organizational learning: putting theory into practice (pp. 75-95). Gower Publishing Limited, UK.

Larbi, G. A. (1999). The New Public Management Approach and Crisis States, UNRISD Discussion Paper, No. 112, Geneva, Switzerland, 1999, pp. 2- 15.

Lipshirtz, R. (2000). Cited by Sun, P. Y., \& Scott, J. L., (2003). Exploring the divide Organizational learning and learning Organization. The learning Organization, 10(4), 202-215.

Lopez, S. P., Peon, J. M., and Ordas, J. V., (2005). Organizational Learning as a Determining Factor in Business Performance. The Learning Organization, 12(3), 227-245.

Lynn, L. E. Jr. (1996). Public Management as Art, Science and Profession (pp. 35-39). Chatham, NJ: Pittsburgh, PA University of Pittsburgh Press.

March, J. (1991). Exploration and Exploitation in organizational learning. Organization Science, 2, 71-87.

Marshall, J., Smith, S., \& Buxton, S. (2009). Learning organization and organizational learning: What have we learned? Management Services, 53(3), 36-43.

Miller, D. A. (1996). A preliminary typology of Organizational learning: Synthesizing the Literature. Strategic Management Journal, 22, 484-505.

Milway, K. S., \& Saxton, A. (2011). The Challenge of Organizational Learning, Stanford, social innovation review, May 20, 2011, pp. 1-8.

Moore, M. (1995). Creating Public Value Strategic Management in Government (pp. 46-51). Cambridge, MA: Harvard University Press.

Murray, P., \& Donegan, K. (2003). Empirical Linkages between firm competencies and organizational learning. The Learning Organization, 10(1), 51-62.

Nevis, E. C., Debila, A. J., \& Gould, J. M., (1995). Cited by Lopez, S. P. et al,. (2005). Organizational Learning as a Determining Factor in Business Performance. The Learning Organization, 12(3), 227-245.

Njuguna, J. I. (2009). Strategic positioning for sustainable competitive advantage: an organizational learning approach. KCA Journal of Business Management, 2(1), 32-44.

Nonaka, I. (1991). The knowledge-creating company. Harvard Business Review, 69(6), 96-104.

Omran, W. (2013). Bad Governance and Failure of Development Progress in Egypt: Causes, Consequences and Remedies. Journal of Public Administration and Governance, 3(4), 39-59.

Omran, W. (2015). A framework for results based management to the public sector in Egypt: challenges and opportunities. Journal of Public Administration and Governance, 5(4), 8-11. 
Oyejide, A. T., \& Bankole, A. S. (2001). Liberalization of the services sector in Nigeria: Implications of unilateral and multilateral approaches. Nigeria: AERC, pp.13-19.

Oyeniyi, O. (2011). Organizational learning and sustainable competitive advantage. Journal of Economics and Business Research, 27(1), 102-117.

Pawlowsky, P. (2003). The Treatment of Organizational Learning in Management Science. In Dierkes, Antal, Child \& Nonaka (Eds.), Handbook of Organizational Learning \& Knowledge (pp. 62-88). Oxford: Oxford University Press.

Pedler, M., Burgoyne, J., \& Boydell, T. (1991). The Learning Company. A strategy for sustainable development, London: McGraw-Hill, pp. 3-5.

Pollitt, C. (1994). Modernizing the Management of the Public Services Sector: Between Crusade and Catastrophe? Paper Presented to the Administrative Development Agency, Helsinki, Finland. pp. 23-42.

Porter, M. E. (1985). Competitive Advantage; Creating and Sustaining Superior Performance (pp. 23-35). New York: The Free Press.

Rebelo, T. M., \& Gomes, A. D. (2008). Organizational learning and the learning organization: Reviewing evolution for prospecting the future. The learning organization, 15(4), 294-308.

Senge, P. (1990). The fifth Discipline: The Art and Practice of the Learning Organization, New York: Doubleday, pp. 11-15.

Senge, P. M. (1990). The Leader's New Work: Building Learning Organizations. Sloan Management Review, Fall, 7-23.

Sinkula, J. M. (1994). Market Information Processing and Organizational Learning. Journal of Marketing, 58, 35-45.

Smith, I. W. (2004). Continuing professional development and workplace learning 6: HRD and organizational learning. Library Management, 25(1), 64-66.

Spender, J. C., \& Grant, R. (1996). Knowledge and the firm: Overview. Strategic Management Journal, Special Issue, 5-11.

Stata, R. (1989), Organizational learning: The key to management innovation. Sloan Management Review, 30, 63-74.

Stewart, J. (1996). Managing Change through Training and Development (pp. 56-71). London: Kogan Page.

Sun, P. Y. T., \& Scott, J. L. (2003). Organizational learning and learning organization. The Learning Organization, 10(4), 202-215.

Teece, D., Pisano, G., \& Shuen, A. (1997). Dynamic capabilities and strategic management. Strategic Management Journal, 18(7), 509-534. 
Trim, P. R. J., \& Lee, Y. (2004). Enhancing customer service and organizational learning through qualitative research. Qualitative Market Research: An International Journal, 7(4), 284-292.

Watkins, K., \& Marsick, V. (1992). Building the learning organization: a new role for human resource developers. Studies in Continuing Education, 14(2), 115-29.

Watkins, K., \& Marsick, V. (Eds.) (1993). Sculpting the Learning Organization. Lessons in the art and science of systematic change (pp. 37-49). San Francisco: Jossey-Bass.

Winter, S. (2000). The Satisfying Principle in Capability Learning. Strategic Management Journal, 21, 981-96.

Yang, B., Watkins, E. K., \& Marsick, J. V. (2004). The construct of the learning organization: dimensions, measurement, and validation. Human Resource Development Quarterly, 15(1), 31-55.

Yassin, E. (Ed.). (1994). Egyptian Bureaucracy, an Empirical Study. Cairo: Al Ahram Center for Political and Strategic Studies, pp. 12-15.

- www.Egypt government service portal.com (accessed 27/12/2015).

- www.global Competitiveness Report .com (accessed 11/12/2015).

\section{Copyright Disclaimer}

Copyright for this article is retained by the author(s), with first publication rights granted to the journal.

This is an open-access article distributed under the terms and conditions of the Creative Commons Attribution license (http://creativecommons.org/licenses/by/3.0/). 